\title{
Numerical evaluation of the measurement error of temperature by surface thermocouples in the conditions of incomplete thermal contact with object of measurement
}

\author{
Yuliana K. Atroshenko and Pavel A. Strizhak \\ National Research Tomsk Polytechnic University, 634050 Tomsk, Russia
}

\begin{abstract}
One-dimensional and two-dimensional models of heat transfer are given in operation for research of the main characteristics of process of temperature measurement by means of surface thermocouples. Results of numerical evaluations of the relative error of the measurement arising owing to existence of air gap between a sensitive element of the thermocouple and object of measurement are provided. It is revealed that the measurement error in case of observance of necessary time of heating up (set minimum required time of measurement) can be lowered to level of an allowed error.
\end{abstract}

\section{Introduction}

Nowadays, temperature measurement is an integral part of productions of all industries and in all fields of activity of the person. Temperature measurement is executed as with I aim monitoring of quality of course of technological processes, and in systems of regulation of technological parameters. Thermo transformers are used for remote temperature measurement, and also for transmission of measuring information from management system resistance or thermocouple. The sensor type selection, mainly, is carried out depending on the range of taken temperatures, the admissible size of the sensitive element necessary for time of establishment of indications and requirements to accuracy of measurements. Thermocouples are used in case of temperature measurement in monitoring systems or the regulations, measurements not requiring to high accuracy, and/or in cases when the fast response to change of the measured parameter-temperature [1] is necessary. Nevertheless, time of establishment of indications in a thermocouple usage time for temperature measurement of a surface of any body, can be increased significantly for a number of reasons. It has rather great impact on the accuracy of measurements in case of non-compliance with necessary duration of heating of a sensitive element.

For saving accuracy of determination of temperature by thermocouples in case of temperature measurement of a surface of object of measurement it is expedient to use prognostic models of nonstationary process of heat transfer in system "object of measurement-the thermocouple". A row of operations [2-4] is devoted to development of such models, nevertheless, the operations devoted to process of heat transfer in the thermocouple from the point of view of prediction of necessary duration of heating up practically aren't present.

This is an Open Access article distributed under the terms of the Creative Commons Attribution License 4.0, which permits unrestricted use, distribution, and reproduction in any medium, provided the original work is properly cited. 


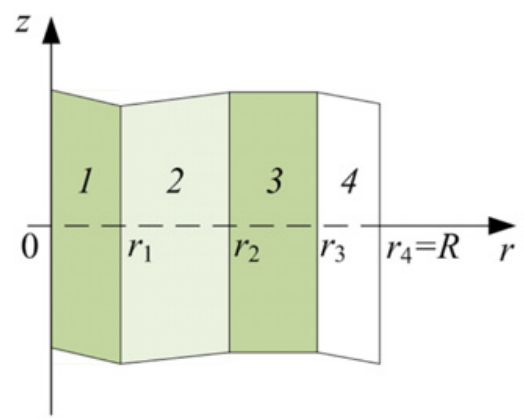

a)

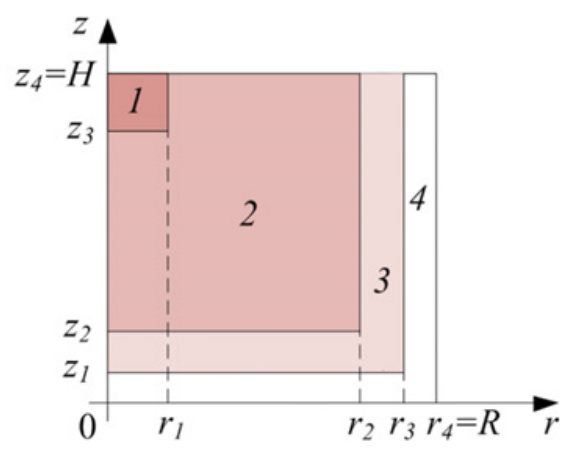

b)

Figure 1. Diagrams of area of the decision one-dimensional (a) and two-dimensional (b) of tasks of heat conduction: 1 - thermocouple junction; 2 - powder $\mathrm{Al}_{2} \mathrm{O}_{3} ; 3$ - protective cover; 4 - air gap.

Requirements to thermocouples, and also requirements to the accuracy of measurements contain in the International standards [5, 6]. In particular, the standard [5] defines eight types of thermocouples. In practice for measurement of temperatures in the range from $-200{ }^{\circ} \mathrm{C}$ to $+1100{ }^{\circ} \mathrm{C}$ in measuring systems of temperature broad application was found only by thermocouples of types L, K, E. As reference thermocouples thermocouples of types $\mathrm{S}$ and $\mathrm{R}$ are applied. Allowed errors of all thermocouples are given in the standard [6]. It is necessary to mark that the measurement error of temperature includes a systematic and accidental component. Thus the accidental error in a certain level is defined by duration of execution of measurements and can be reduced by prediction of optimum duration of heating of the thermocouple.

The submersible thermocouples which are applying to temperature measurement of different environments, as a rule, possess rather small duration of establishment of indications. Time of response for change of the taken temperature for surface thermocouples substantially is defined by value of air gap between a surface of the thermocouple and object of measurement. Determination of necessary time of heating up of the thermocouple can be executed by means of numerical modeling of nonstationary process of heat transfer in the non-uniform system "the thermocouple - air gap - object of measurements".

\section{Physical model of heat transfer}

In development process of prognostic model of heat transfer one-dimensional and two-dimensional tasks of heat conduction were considered, diagrams of which area of the decision are provided in Fig. 1.

The following assumptions are accepted in case of numerical modeling:

1) Heat-physical characteristics of the materials entering area of the solution of the task don't depend on temperature;

2) Temperature change within area of the solution of the task (Fig. 1a) happens only in the direction of cylindrical coordinate of $r$ (for one-dimensional setting).

The end of process of heating up was defined at the time of achievement by a thermocouple junction of temperature, other than an allowed error measured on value. Values of allowed errors are given in Table 1.

For area solutions of the task (Fig. 1) are made the following sizes: $\mathrm{H}=5 \mathrm{~mm} ; \mathrm{R}=5 \mathrm{~mm}$. Thickness of air gap between object of measurement and the thermocouple (along coordinates of $\mathrm{z}$ and $\mathrm{r}$ ) varied when carrying out numerical modeling in the range from $1 \mathrm{~mm}$ to $3 \mathrm{~mm}$. 
Table 1. Limits of allowed errors of thermocouple [6].

\begin{tabular}{|l|l|}
\hline Thermocouple's type & Permissible deviation limit from rated direct current characteristic, ${ }^{\circ} \mathrm{C}$ \\
\hline$L(2$ tolerance class $)$ & $\begin{array}{l} \pm 2,5 \text { in the range of temperatures from }-40 \text { to } 300{ }^{\circ} \mathrm{C} ; \\
\pm 0,0075 \cdot t \text { in the range of temperatures from } 300 \text { to } 800{ }^{\circ} \mathrm{C}\end{array}$ \\
\hline$S(2$ tolerance class $)$ & $\pm 1,5$ in the range of temperatures from 0 to $600{ }^{\circ} \mathrm{C}$ \\
\hline$K$ (1 tolerance class $)$ & $\begin{array}{l} \pm 1,5 \text { in the range of temperatures from }-40 \text { to } 375{ }^{\circ} \mathrm{C} \\
\pm 0,004 \cdot t \text { in the range of temperatures from } 375 \text { to } 1000{ }^{\circ} \mathrm{C}\end{array}$ \\
\hline
\end{tabular}

\section{Mathematical model and decision methods}

The system of differential equations describing process of heattransfer within one-dimensional model, has the following appearance:

$$
\begin{array}{cl}
c_{1} \rho_{1} \frac{\partial T_{1}}{\partial t}=\frac{\lambda_{1}}{r} \frac{\partial}{\partial r}\left(r \frac{\partial T_{1}}{\partial r}\right), & t>0,0<r<r_{1}, \\
c_{2} \rho_{2} \frac{\partial T_{2}}{\partial t}=\frac{\lambda_{2}}{r} \frac{\partial}{\partial r}\left(r \frac{\partial T_{2}}{\partial r}\right), & t>0, r_{1}<r<r_{2}, \\
c_{3} \rho_{3} \frac{\partial T_{3}}{\partial t}=\frac{\lambda_{3}}{r} \frac{\partial}{\partial r}\left(r \frac{\partial T_{3}}{\partial r}\right), & t>0, r_{2}>r<r_{3}, \\
c_{4} \rho_{4} \frac{\partial T_{4}}{\partial t}=\frac{\lambda_{4}}{r} \frac{\partial}{\partial r}\left(r \frac{\partial T_{4}}{\partial r}\right), & t>0, r_{3}<r<r_{4} .
\end{array}
$$

The two-dimensional model is described by system of equations:

$$
\begin{gathered}
c_{1} \rho_{1} \frac{\partial T_{1}}{\partial t}=\lambda_{1}\left(\frac{\partial^{2} T_{1}}{\partial r^{2}}+\frac{1}{r} \frac{\partial T_{1}}{\partial r}+\frac{\partial^{2} T_{1}}{\partial z^{2}}\right), t>0,0<r<r_{1}, z_{3}<z<H \\
c_{2} \rho_{2} \frac{\partial T_{2}}{\partial t}=\lambda_{2}\left(\frac{\partial^{2} T_{2}}{\partial r^{2}}+\frac{1}{r} \frac{\partial T_{2}}{\partial r}+\frac{\partial^{2} T_{2}}{\partial z^{2}}\right), t>0,0<r<r_{2}, z_{2}<z<z_{3} ; r_{1}<r<r_{2}, z_{3}<z<H ; \\
c_{3} \rho_{3} \frac{\partial T_{3}}{\partial t}=\lambda_{3}\left(\frac{\partial^{2} T_{3}}{\partial r^{2}}+\frac{1}{r} \frac{\partial T_{3}}{\partial r}+\frac{\partial^{2} T_{3}}{\partial z^{2}}\right), t>0,0<r<r_{3}, z_{1}<z<z_{2} ; r_{2}<r<r_{3}, z_{2}<z<H ; \\
c_{4} \rho_{4} \frac{\partial T_{4}}{\partial t}=\lambda_{4}\left(\frac{\partial^{2} T_{4}}{\partial r^{2}}+\frac{1}{r} \frac{\partial T_{4}}{\partial r}+\frac{\partial^{2} T_{4}}{\partial z^{2}}\right), t>0,0<r<L, 0<z<z_{1} ; r_{2}<r<r_{3}, z_{2}<z<H
\end{gathered}
$$

Where $\mathrm{r}$ - radial coordinate, $\mathrm{m}$; $\mathrm{z}$ - axial coordinate, $\mathrm{m} ; \rho$ - density, $\mathrm{kg} / \mathrm{M} 3$; $\mathrm{c}$ - specific heat capacity, $\mathrm{J} /\left(\mathrm{kg} \cdot{ }^{\circ} \mathrm{C}\right) ; \lambda$ - coefficient of heat conduction, $\mathrm{W} /\left(\mathrm{m} \cdot{ }^{\circ} \mathrm{C}\right)$; indexes: 1 - thermocouple's junction, $2-$ powder of an oxide of aluminum, 3 - a protective cover, 4 - air. 
Temperature distribution in an initial time-point in the system making area of the solution of the task are defined by the following initial conditions:

$$
t=0 ; T=T_{0}, 0<r<R, 0<z<H,
$$

where $T_{0}$ - temperature corresponding to reference conditions: $T_{0}=20^{\circ} \mathrm{C}$.

The boundary conditions which have been set on an axis of symmetry $r=0$ :

$$
r=0, \frac{\partial T}{\partial r}=0
$$

Boundary conditions on boundary $r=R$ :

$$
r=R ; T=T_{r}
$$

$T_{r}$ - temperature of a heating element.

Boundary conditions on boundaries on an axis $z$ :

$$
z=H, \frac{\partial T}{\partial r}=0 ; z=0, T=T_{r} .
$$

On boundaries "an $\mathrm{Al}_{2} \mathrm{O}_{3}$ thermocouple powder seal", "the powder $\mathrm{Al}_{2} \mathrm{O}_{3}$-protective a cover", "a protective cover air" (Fig. 1) conditions of the IV kind were accepted:

$$
\left\{\begin{array} { l } 
{ T _ { 1 } ( r _ { 1 } , z ) = T _ { 2 } ( r _ { 1 } , z ) ; } \\
{ - \lambda _ { 1 } \frac { \partial T _ { 1 } } { \partial r } | _ { r = r _ { 1 } } = - \lambda _ { 2 } \frac { \partial T _ { 2 } } { \partial r } | _ { r = r _ { 1 } } ; } \\
{ T _ { 2 } ( r _ { 2 } , z ) = T _ { 3 } ( r _ { 2 } , z ) ; } \\
{ - \lambda _ { 2 } \frac { \partial T _ { 2 } } { \partial r } | _ { r = r _ { 2 } } = - \lambda _ { 3 } \frac { \partial T _ { 3 } } { \partial r } | _ { r = r _ { 2 } } ; \quad ( 1 2 ) } \\
{ T _ { 3 } ( r _ { 3 } , z ) = T _ { 4 } ( r _ { 3 } , z ) ; } \\
{ - \lambda _ { 3 } \frac { \partial T _ { 3 } } { \partial r } | _ { r = r _ { 3 } } = - \lambda _ { 4 } \frac { \partial T _ { 4 } } { \partial r } | _ { r = r _ { 3 } } ; }
\end{array} \quad \left\{\begin{array}{l}
T_{1}\left(r, z_{3}\right)=T_{2}\left(r, z_{3}\right) ; \\
-\left.\lambda_{1} \frac{\partial T_{3}}{\partial z}\right|_{z=z_{3}}=-\left.\lambda_{2} \frac{\partial T_{2}}{\partial z}\right|_{z=z_{3}} ; \\
T_{2}\left(r, z_{2}\right)=T_{3}\left(r, z_{2}\right) ; \\
-\left.\lambda_{2} \frac{\partial T_{2}}{\partial z}\right|_{z=z_{2}}=-\left.\lambda_{3} \frac{\partial T_{3}}{\partial z}\right|_{z=z_{2}} ; \\
T_{3}\left(r, z_{1}\right)=T_{4}\left(r, z_{1}\right) ; \\
-\left.\lambda_{3} \frac{\partial T_{3}}{\partial z}\right|_{z=z_{1}}=-\left.\lambda_{4} \frac{\partial T_{4}}{\partial z}\right|_{z=z_{1}}
\end{array}\right.\right.
$$

Conditions (12) are valid for one-dimensional model, conditions were applied to two-dimensional model (12), (13).

The area of the solution of the task (Fig. 1) is broken into the uniform grid consisting of 240 nodes. The slot pitch on radial and axial coordinates is equal $2.5 \cdot 10^{-2} \mathrm{~mm}$. The step on a temporal grid changed in the range from $10^{-4}$ to $10^{-2} \mathrm{~s}$ for reduction of volume of computation and increase of accuracy of the decision.

Systems of Eqs. (1)-(4) and (5)-(8) with the appropriate initial and boundary conditions decided using a method of finite differences [7]. The solution of the difference analogs of the differential equations representing linear algebraic equations was carried out by a local and one-dimensional method [7]. The pro-race method was applied to the decision of system of the difference equations on the basis of the implicit four-point diagram [7].

The conservatism verification of applied difference schemes was conducted to estimate the confidence of numerical simulation results similar to [8-10]) and the comparison with experiment results was accomplished.

\section{Results and discussion}

Heat-physical characteristics of basic elements of considered systems are provided in Table 2 .

The described models were used for research of necessary duration of heating up of different types of thermocouples $-\mathrm{K}, \mathrm{L}, \mathrm{S}$. Results of numerical modeling are given in Table 3. 
Table 2. Heat-physical characteristics of materials [11].

\begin{tabular}{|c|l|c|c|l|}
\hline $\begin{array}{c}\text { No } \\
\text { material } \\
\text { (Fig. 1) }\end{array}$ & Name of the material & $\begin{array}{c}\text { Specific heat } \\
\text { capacity c, } \\
\mathrm{J} /\left(\mathrm{kg} \cdot{ }^{\circ} \mathrm{C}\right)\end{array}$ & $\begin{array}{c}\text { Heat conduction } \\
\text { coefficient } \lambda, \\
\mathrm{W} /\left(\mathrm{m} \cdot{ }^{\circ} \mathrm{C}\right)\end{array}$ & $\begin{array}{l}\text { Density } \\
\rho, \mathrm{kg} / \mathrm{m} 3\end{array}$ \\
\hline 1 & Thermocouple's junction type S & 139 & 50.4 & 20710 \\
\hline 1 & Thermocouple's junction type L & 713 & 24.75 & 8920 \\
\hline 1 & Thermocouple's junction type K & 768 & 33.1 & 8825 \\
\hline 2 & Powder Al2O3 & 850 & 6.57 & 1520 \\
\hline 3 & Stainless steel sheath steel & 462 & 15 & 7900 \\
\hline 4 & Air & 1190 & 0.026 & 1.161 \\
\hline
\end{tabular}

Table 3. Duration of heating up of the TEP sensitive element, s.

\begin{tabular}{|c|c|c|c|c|c|c|}
\hline & $\begin{array}{c}\text { Two- } \\
\text { dimensional } \\
\text { model }\end{array}$ & $\begin{array}{c}\text { One- } \\
\text { dimensional } \\
\text { model }\end{array}$ & $\begin{array}{c}\text { Two- } \\
\text { dimensional } \\
\text { model }\end{array}$ & $\begin{array}{c}\text { One- } \\
\text { dimensional } \\
\text { model }\end{array}$ & $\begin{array}{c}\text { Two- } \\
\text { dimensional } \\
\text { model }\end{array}$ & $\begin{array}{c}\text { One- } \\
\text { dimensional } \\
\text { model }\end{array}$ \\
\hline & \multicolumn{2}{|c|}{ L type } & \multicolumn{2}{c|}{ K type } & \multicolumn{2}{c|}{ S type } \\
\hline 300 & 49.976 & 215.435 & 74.801 & 324.147 & 72.379 & 298.494 \\
\hline 350 & 150.959 & 651.955 & 176.060 & 763.890 & 170.492 & 703.770 \\
\hline 400 & 181.285 & 783.043 & 206.470 & 895.946 & 199.956 & 825.475 \\
\hline 450 & 199.748 & 862.851 & 224.990 & 976.344 & 217.894 & 899.571 \\
\hline 500 & 213.061 & 920.399 & 238.340 & 1034.300 & 230.828 & 953.000 \\
\hline 550 & 223.479 & 965.433 & 248.780 & 1079.700 & 240.951 & 994.811 \\
\hline 600 & 232.963 & 1009.000 & 257.370 & 1117.000 & 249.268 & 1029.200 \\
\hline 650 & 233.377 & 1008.200 & 264.400 & 1147.500 & 256.327 & 1058.300 \\
\hline 700 & 233.692 & 1009.600 & 264.710 & 1148.900 & 262.459 & 1083.700 \\
\hline 750 & 233.939 & 1010.600 & 264.960 & 1149.900 & 267.880 & 1106.000 \\
\hline 800 & 234.303 & 1011.500 & 265.160 & 1150.800 & 272.737 & 1126.100 \\
\hline 850 & 234.506 & 1012.200 & 265.320 & 1151.500 & 277.138 & 1144.300 \\
\hline
\end{tabular}

For the thermocouple of $\mathrm{L}$ type at a temperature over $570 \mathrm{~K}$ and for the thermocouple of $\mathrm{K}$ type at a temperature over $650 \mathrm{~K}$ necessary duration of heating up increases slightly because the allowed error in the specified range of temperatures has not constant character but depends on the taken temperature.

The results received by means of one-dimensional model considerably differ from the results defined by two-dimensional model. It is caused by that the two-dimensional model considers process of heating not only from vertical boundaries but also from lower bound. However the one-dimensional model can be used for prediction of time of heating up of the thermocouples placed in the furnaces or heating cameras which length considerably exceeds diameter of the thermocouple.

Dependences of the relative error of measurements on duration of heating up of the thermocouple of L type are given in Fig. 2 up to the temperature of $550 \mathrm{~K}$ in case of different values of value of air gap.

The Fig. 2 testifies that duration of heating up of the thermocouple can promote measuring accuracy increase. Value of air gap has essential impact on a measurement error in case of non-compliance with minimum necessary time of heating up of the thermocouple.

Dependences of the relative error of measurement of different temperatures are given in Fig. 3 in case of value of air gap of $1 \mathrm{~mm}$ between the thermocouple and object of measurement.

The dependences provided in Fig. 3 testify that in the presence of air gap between the thermocouple and object of measurement the error on condition of satisfaction of the thermocouple to all technical requirements can be reduced by means of observance of minimum necessary duration of heating up of the thermocouple.

Temperature measurement error depending on assignment of measurement can have a negative impact on a row of factors. In particular, in a usage time of a measuring signal of temperature in 


\section{EPJ Web of Conferences}

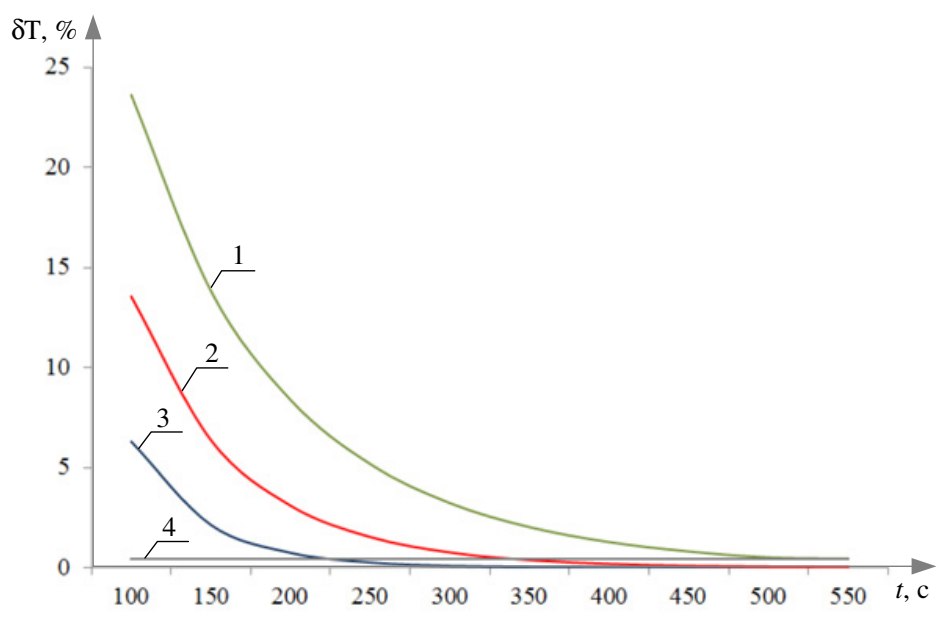

Figure 2. Dependence of the relative error of temperature measurement on duration of heating up of the thermocouple of L type up to the temperature of $550 \mathrm{~K}: 1$ - value of air gap of $3 \mathrm{~mm}, 2$ - value of air gap of $2 \mathrm{~mm}, 3$ - value of air gap of $1 \mathrm{~mm}, 4$ - an allowed error.

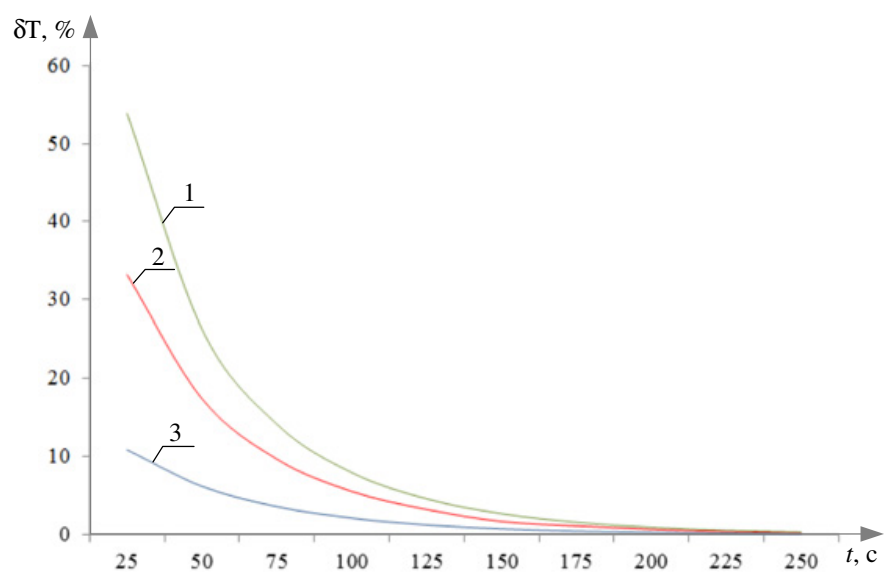

Figure 3. Dependence of the relative error of measurement on duration of heating up of the thermocouple of L type in the conditions of air gap of $1 \mathrm{~mm}$ at temperatures: $1-700 \mathrm{~K}, 2-550 \mathrm{~K}, 3-350 \mathrm{~K}$.

management systems as signals on which regulation is carried out can lead to erratic establishment of adjustable parameter that can cause an excessive consumption of fuel, damage of technology equipment and to other negative consequences.

\section{Conclusion}

By results of numerical research of process of heat transfer in case of thermocouple heating up, it is possible to draw the following outputs:

1) the one-dimensional model can't be used for prediction of necessary duration of heating up of the thermocouple used for temperature measurement of a surface of object in the conditions of heating up from the lower and vertical boundaries; 
2) value of air gap has essential impact on a measurement error, thus, error reduction in this case can achieve, observing minimum necessary time of heating up of the thermocouple;

3) numerical modeling of process of heat transfer can be used for determination of duration of heating up of the thermocouple up to the given temperature in case of what the necessary duration of heating slightly changes in the field of temperatures in which the allowed error has no constant value, but is defined by the taken temperature.

This work was supported by the Russian Foundation for Basic Research (No. 14-08-00057).

\section{References}

[1] J. Sulciner, Control Engineering, 46, 152 (1999)

[2] T. V. Borovkova, V. N. Yeliseyev, and I.I. Lopukhov, Physics of Particles and Nuclei Letter, 5, 274 (2008)

[3] G. V. Kuznetsov and K. M. Mukhammadeev, Journal of Engineering Thermophysics, 19, 17 (2010)

[4] A. E. Segall, International Journal of Heat and Mass Transfer, 44, 2801 (2001)

[5] IEC 60584-1. International standard. Thermocouples. Part 1: Reference tables, 1995

[6] IEC 60584-2. International standard. Thermocouples. Part 2: Tolerances, 1989

[7] A.A. Samarskii, The Theory of Difference Schemes (Marcel Dekker, Inc., USA, 2001)

[8] G.V. Kuznetsov G.V. and P.A. Strizhak, International Journal of Heat and Mass Transfer, 53, 923 (2010)

[9] D.O. Glushkov, G.V. Kuznetsov, P.A. Strizhak, Russian Journal of Physical Chemistry B., 1000 (2011)

[10] D.O. Glushkov, P.A. Strizhak, Journal of Engineering Thermophysics, 69 (2012)

[11] N.B. Vargaftik, L.P. Filipov, A.A. Tarzimanov, E. E. Totskii, Handbook of Thermal Conductivity of Liquids and Gases, CRC Press, Inc., Boca Raton, 1994 